\title{
Writing the Research Proposal: The Art and the Science
}

Research is to see what everybody else has seen, and to think what nobody else has thought

—Albert Szent-Györgyi, Hungarian Biochemist (1893-1986)

No Research without Action, No Action without Research

—Kurt Lewin, German-American psychologist (1890-1947)

\subsection{What Is a Research Proposal?}

A research proposal is a document containing details about the research which is to be undertaken. It should be self-contained and start with a fundamental enquiry related to the research questions(s) and the hypothesis (es) on which it is based. The objectives and key questions are the fundamental pillars of a research proposal and formal grant application.

A study protocol, often used for clinical trials, is a document that describes the objectives, elucidates the methodology, ethical considerations (consent process) as well as the overall execution template to guide the research [1]. Journals dedicated to studying protocols also encourage publication of research protocols prior to the wrap-up and conclusion of studies to encourage transparency and avoid duplication of research.

A research proposal can be in a free form or follow a suggested format, usually prescribed by the science funding body or organization. In general, a proposal format includes:

- The Title

- Abstract 
- Background and Rationale

- Aims and Objectives of the study

- Details of the Research Question

- Methodology

- Ethical considerations

- Details of the primary investigator, co-investigator. Internal and external collaborators.

- Estimated Budget

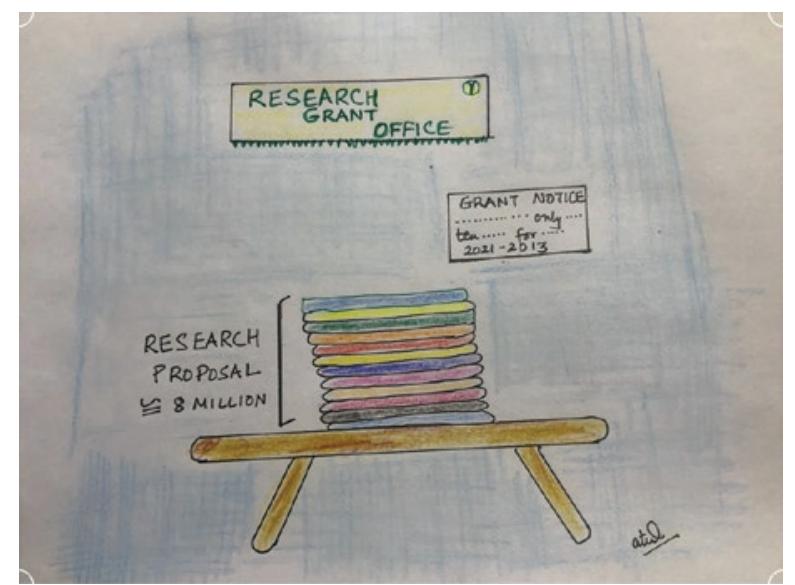

\subsubsection{The Title}

The title should be composed of key substantive words, which may include the characteristics and geographical location of research, the sample population as well as a hint of the result. The title may at times be interrogative.

For example, the title of this study protocol-Study protocol of a cluster randomized controlled trial to evaluate the effectiveness of a system for maintaining highquality early essential newborn care in Lao PDR [2]. conveys the study design, i.e., the cluster randomized trial, the purpose of the research and also the study population and site of the research.

Many grant organizations have specific requirements for space and characters for titles, so ensure conformity with those. 


\subsubsection{Abstract}

Some organizations require an abstract or an executive summary at the beginning of the research proposal. This is a brief precis and description of your research project, background, methods, and analytical plan.

\subsubsection{Background and Rationale}

What is already known about this research area? Have there been any previous studies already addressing this issue? Many research funding bodies expect the investigators to cite a systematic review related to the subject area, typically the most credible review available on the subject. The literature review ought to highlight why the research question being addressed in the project is important.

\subsubsection{Aims and Objectives of the Research}

The primary goals of the research study are described in terms of its aims and objectives. Aims are general and broad statements that state the intent of the researchers and what they hope to achieve, while objectives are more specific that describe the path to achieving those aims.

Aims and Objectives are encouraged to follow the SMART criteria:

- Specific-Precision about what is going to be done

- Measurable-Outcomes clearly defined

- Attainable-Can be possibly achieved and not overly ambitious

- Realistic-Possible in the presence of available resources, e.g., finances, time, and manpower

- Time Constrained-Bound by time

\subsubsection{Details of the Research Question}

The PICOT format (Population, Intervention, Control or comparison group, Outcome of disease, Time, or Type of study) helps to frame a good research question.

\subsubsection{Methodology}

The Methodology section follows the background and literature review so should organically follow through with a recapitulation of your research question, the related scholarly research available, and your own aims and objectives [3]. 
This section attempts to answer the $5 \mathrm{~W}$ and One $\mathrm{H}$ questions-Who, What, When, Where, Why and How.

This section should be written carefully in full detail in such a way that anyone who reads it can replicate the experiment; if it is a new statistical model that you propose, you should be able to apply it to your own dataset. This section is like a road map that helps the investigator to navigate the planned study and should be written in the future tense. The methodology section should not just state the methods chosen, but should appropriately justify why it was selected based on sound scholarly research. It should also discuss the limitations in the proposed methods and compromises made based on existing constraints, for example, the choice of sampling and the inclusion and exclusion criteria. This section should include the following details [3]:

\subsubsection{Study Area/Location}

This subsection states the institutional and departmental affiliation or the site where the research is to be conducted. If it is clinical research, data on the patient enrolment area, patient catchment area and patient recruitment area, and whether they were from the outpatient or inpatient departments.

In other instances, with population-based research, the study population may be a community, region, or even a larger population aggregate, comprising the universe of the study from which subjects will be recruited.

\subsubsection{Study Population}

The enrolment should always be according to a pre-defined population. The inclusion and exclusion criteria to be used for the study should also be mentioned in this section.

For example, 'to study the prevalence of lymphoma in Sjogren's syndrome', the inclusion will include all known cases of Sjogren's syndrome and those with a histologically confirmed diagnosis of lymphoma. The exclusion criteria will be lymphoma associated with HIV, hepatitis B and C viral infections, or due to other causes.

\subsubsection{Sample Size}

The number of cases to be recruited into the study should be stated here. The formula that is intended to be used to derive the sample size should also be included as well as the statistical power, the expected prevalence of the disease, or the shift in outcome if relevant. Recent statistical software has made this step much easier so the statistical software employed for these calculations, e.g., EPI INFO should be mentioned.

\subsubsection{Study Design}

The designs are broadly experimental or observational and may utilize primary or secondary data. Differences between both are tabulated in Table 12.1 [4]. 
Table 12.1 Differences between primary and secondary data sources

\begin{tabular}{l|l|l}
\hline Points & Primary data & Secondary data \\
\hline Meaning & $\begin{array}{l}\text { Data collected by researcher } \\
\text { himself }\end{array}$ & Data collected by other people \\
\hline Originality & Original or unique information & Not original or unique information \\
\hline Adjustment & $\begin{array}{l}\text { Does not need adjustment, is } \\
\text { focused }\end{array}$ & Needs adjustment to suit actual aim \\
\hline Sources & $\begin{array}{l}\text { Surveys, observations, } \\
\text { experiments }\end{array}$ & $\begin{array}{l}\text { Internal records, govt. published data } \\
\text { etc. }\end{array}$ \\
\hline Type of data & Qualitative data & Quantitative data \\
\hline Methods & $\begin{array}{l}\text { Observation, experiment, } \\
\text { interview }\end{array}$ & $\begin{array}{l}\text { Desk research method, searching } \\
\text { online etc. }\end{array}$ \\
\hline Reliability & More reliable & Less reliable \\
\hline Time consumed & More time consuming & Less time consuming \\
\hline $\begin{array}{l}\text { Need of } \\
\text { investigators }\end{array}$ & $\begin{array}{l}\text { Needs team of trained } \\
\text { investigators }\end{array}$ & Does not need a team of investigators \\
\hline Cost-effectiveness & Costly & Economical \\
\hline Collected when & Secondary data is inadequate & Before primary data is collected \\
\hline Capability & More capable to solve a problem & Less capable to solve a problem \\
\hline Suitability & $\begin{array}{l}\text { Most suitable to achieve } \\
\text { objective }\end{array}$ & May or may not be suitable \\
\hline Bias & Possibility of bias exist & Somewhat safe from bias \\
\hline Collected by & Researcher or his/her agents & $\begin{array}{l}\text { Persons other than who collects } \\
\text { primary data }\end{array}$ \\
\hline Precaution to use & Not necessary & Quite necessary \\
\hline & &
\end{tabular}

\subsubsection{Study Duration}

The date of initiation and expected completion date are mentioned. The study can start only after the institutional board gives ethical clearance.

\subsubsection{Methodology of the Trial}

In this section, the step-by-step approach of the study is described. It could begin with patient recruitment and the patient consent approval process and could be followed by a description of the physical examination and a systemic examination to be carried out. It should include whether there are tests to be done in the intervention and the length of period after which any change in the intervention will be studied.

\subsubsection{Outcome of the Disease}

This is the most important consequence of the study. Mention what change you are expecting during the experiment. For any disease, the outcome can be:

- Complete recovery

- Incomplete recovery

- Death 
There may also be disease-specific outcome measures like in rheumatology one can use a visual analogue scale, ESR, CRP, Disease Activity Score (DAS), Simplified Disease Activity Index, and Clinical Disease Activity Index.

\subsubsection{Data Collection}

The data collected may be qualitative or quantitative. A protocol for data collection which incorporates and satisfies the requirements of Good Clinical Practice (GCP) should be included. For example, in a study around the effect of pomegranate juice on lipid profile and type 2 diabetes, the systolic and diastolic blood pressures, and the lipid profile of the patients were measured at baseline and end-line following $12-14 \mathrm{~h}$ of fasting (5).

Furthermore, a data analysis plan, a data quality assurance plan, a statistical plan, and a contingency plan for missing and spurious data should also be discussed.

\subsection{What Are Study Designs?}

Experimental studies are further divided into randomized controlled trials or nonrandomized trials. The observational studies are of four types, cohort studies, casecontrol studies, cross-sectional, and ecological studies (Fig. 12.1).

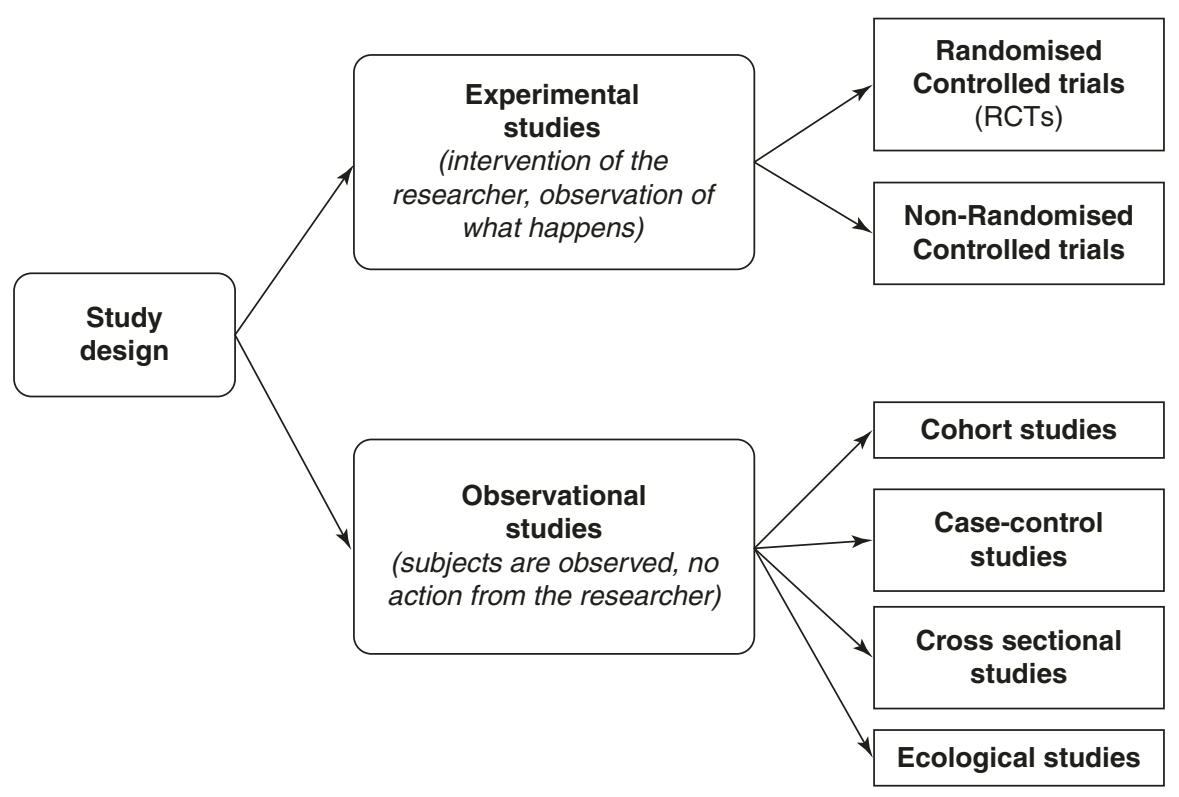

Fig. 12.1 Overview of types of study design 
Table 12.2 Types of interventions

\begin{tabular}{|c|c|}
\hline Intervention & Examples \\
\hline Using a specific drug & $\begin{array}{l}\text { Using iron tablets in adolescent girls in school in one subset of the } \\
\text { population }\end{array}$ \\
\hline Using a vaccine & $\begin{array}{l}\text { Administration of quadrivalent influenza vaccines in one group of } \\
\text { elderly residents of an old age home }\end{array}$ \\
\hline $\begin{array}{l}\text { Use of a dietary } \\
\text { supplement }\end{array}$ & $\begin{array}{l}\text { Use of fenugreek seeds in one group of patients for weight loss in } \\
\text { morbid obesity }\end{array}$ \\
\hline Performing a test & $\begin{array}{l}\text { Performing retHb for predicting the response of iron supplementation } \\
\text { in one subset of a population }\end{array}$ \\
\hline $\begin{array}{l}\text { Using a new surgical } \\
\text { technique }\end{array}$ & Use of robotic techniques for gastric bypass surgery \\
\hline An educational tool & $\begin{array}{l}\text { Use of pictures and flash cards for nurses for segregation of biomedical } \\
\text { waste into waste bins of different colours }\end{array}$ \\
\hline
\end{tabular}

\subsection{What Is an Intervention?}

The intervention can be in the form of treatment using a drug, vaccine, or even a dietary supplement, the use of a diagnostic or therapeutic procedure or the introduction of an educational tool (Table 12.2).

\subsection{What Are the Various Type of Trials with Interventions?}

There are various types of intervention-based trials that are listed below:

\section{- Randomized controlled trials}

In this, a patient in one arm of the trial gets the intervention and the others get the placebo or the standard of care. Randomized Controlled Trials are considered the gold standard in clinical research, and evidence generated is considered to be the highest in the hierarchy of evidence.

- Nonrandomized trials

In this, the intervention is given only to some participants, e.g., those who can afford the drug or vaccine and the others get standard care.

- Interventional studies without concurrent controls

If a new drug is to be given in a particular condition to a study population, historical controls are used (Fig. 12.2).

- Pre- and post-intervention study

An example is the use of an educational tool applied in a specific population the change is noted before and after the intervention.

\section{- Factorial studies}

In this, two or more interventions are examined and their effects are studied collectively and separately. 


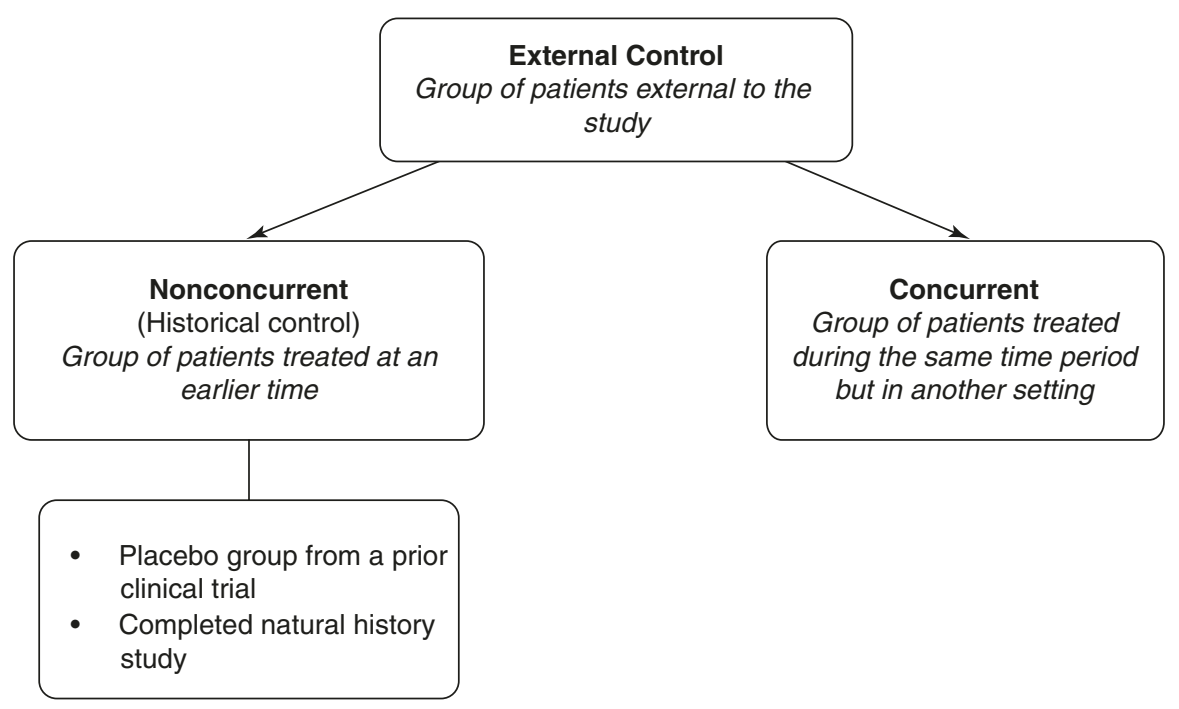

Fig. 12.2 Study with external controls

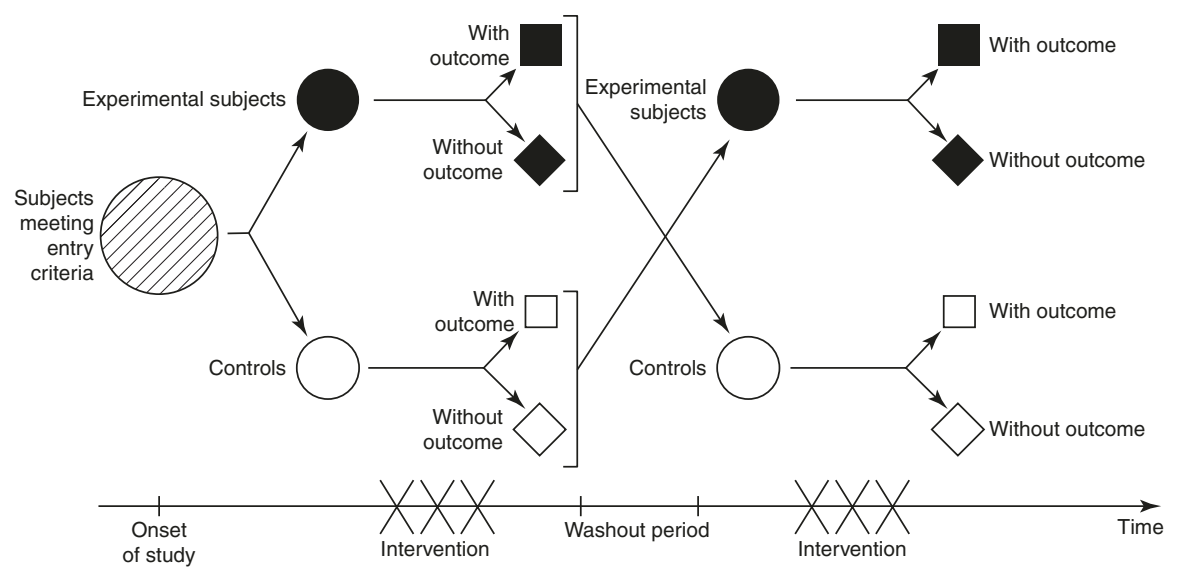

Fig. 12.3 RCT crossover design

\section{- Crossover studies}

Each patient is given one type of intervention and then after a predefined time a washout period is instituted where controls and experimental subjects are swapped and then given the other trial intervention (Fig. 12.3).

\section{- Cluster randomization trials}

The intervention in a single person may be easy to apply but once the trial is done on a community it requires to be studied in a cluster of the population. Units of randomization are clusters, and not individuals. By design, they are large and complex studies but more definitive in terms of health population and systems research.

In the cluster randomized trial in Matiari and Hala in Sindh Pakistan (Fig. 12.4), clusters were allocated to intervention and control groups through stratified randomization. The intervention package included health promotive 


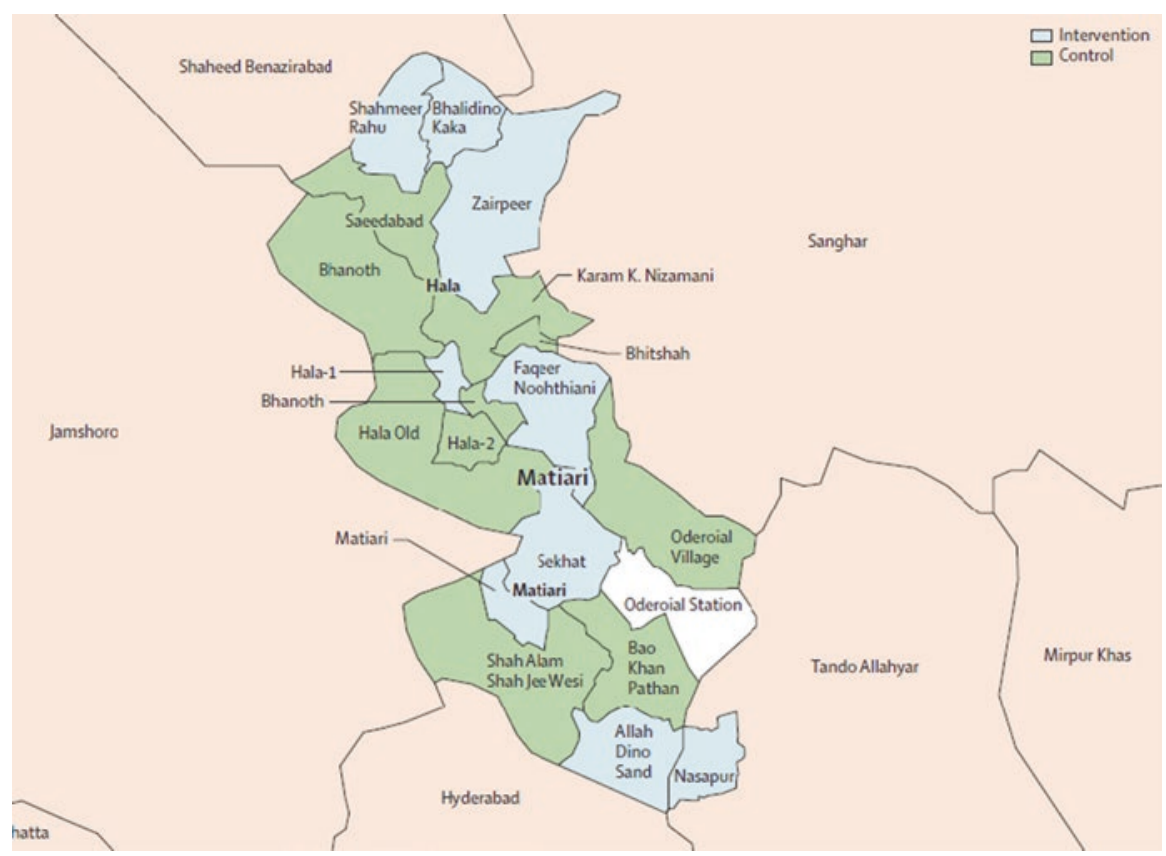

Fig. 12.4 Cluster randomized trial in Matiary and Hala in Sindh Pakistan

Fig. 12.5 Cross-sectional study (Basic design)

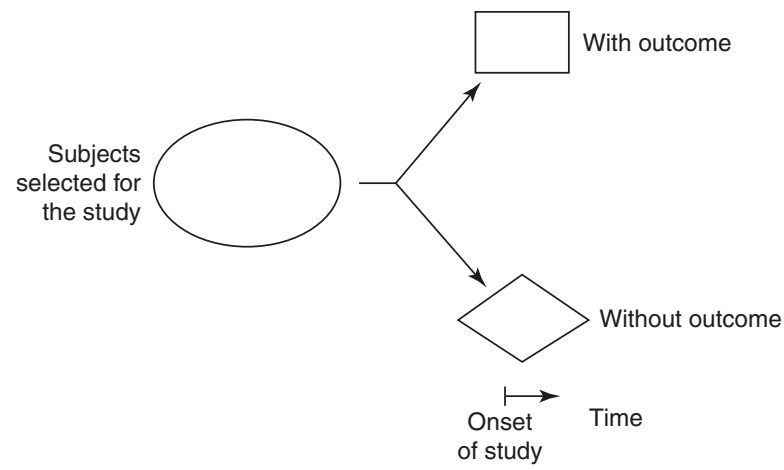

No direction of inquiry

$\mathrm{MNCH}$ activities through community healthcare workers and this RCT. Neonatal mortality rate was lower in intervention clusters at 43.0 deaths per 1000 live births and 49.1 per 1000 in control groups (RR 0.85, 0.76-0.96; $p=0.02$ ) [5].

\subsubsection{Observational Studies}

\subsubsection{Cross-Sectional Study}

These studies represent data collected over a defined period of time, and are often used to calculate the prevalence of a certain disease or condition (Fig. 12.5). 
However, a major limitation is that they do not help establish causality due to unknown temporality. They are also vulnerable to recall error and response bias when questions about the past are assessed.

\subsubsection{Cohort Studies}

This study design is longitudinal in nature and involves following a group of participants who have a particular characteristic in common, for example, they may all be in the same geographical region or in a particular occupation (Fig. 12.6). The study involves following them prospectively and studying associations between exposure and outcome.

\subsubsection{Case-Control Studies}

By definition, case studies are observational and retrospective. Also known as 'casereferent studies'. They are observational because they compare patients who have the disease or outcome of interest (cases) with patients who do not have the disease

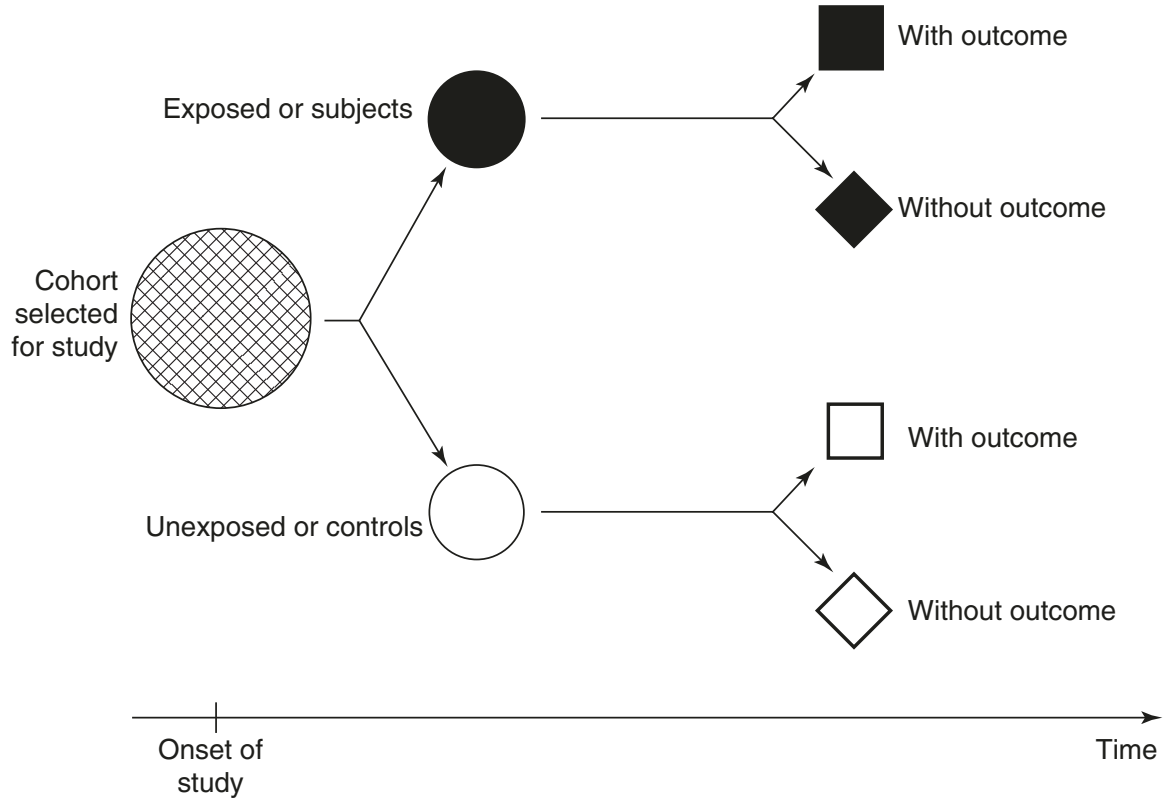

Direction of inquiry

Fig. 12.6 Cohort study (Basic design) 


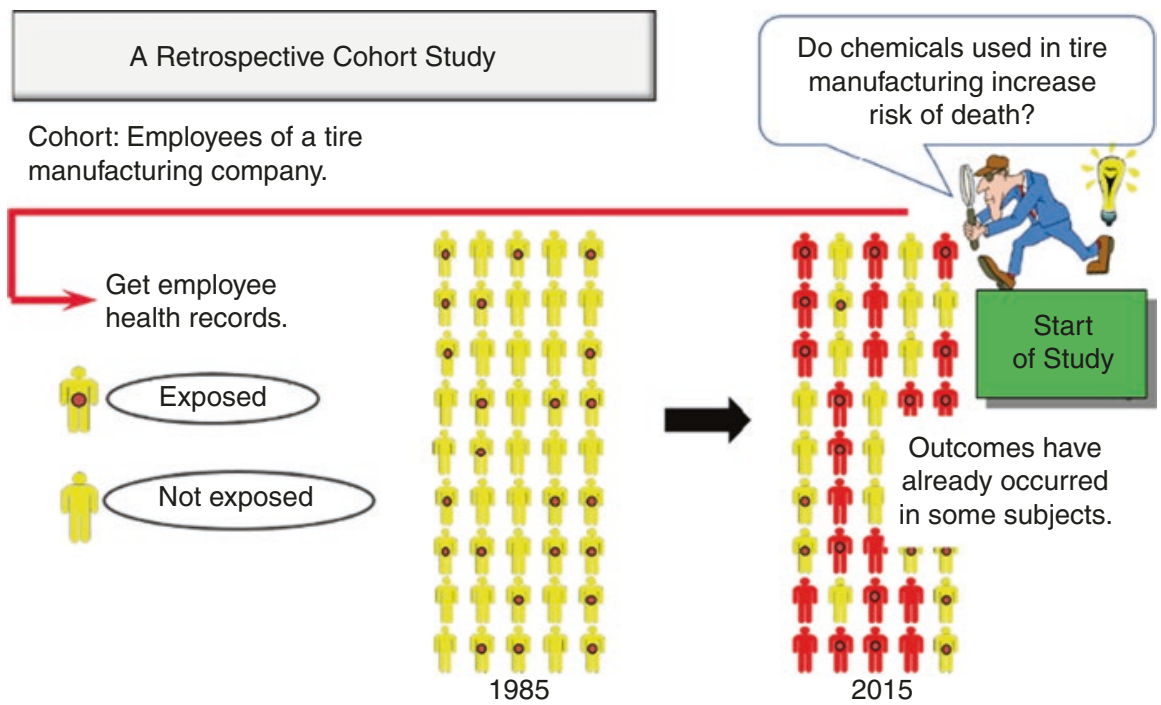

Fig. 12.7 Retrospective study

or outcome (controls) and look back retrospectively to compare how frequently the exposure to a risk factor is associated with the disease (Fig. 12.7).

Case-control studies are observational because no intervention is attempted and no attempt is made to alter the course of the disease. The goal is to retrospectively determine the exposure to the risk factor of interest from each of the two groups of individuals: cases and controls. These studies are designed to estimate odds.

\subsubsection{Ecological Studies}

Ecological studies the association between exposure and disease, but the unit of observation is a community or even a broader regional area such as a country. The ecological study design is relatively cheaper as it often utilizes published populationlevel statistics such as mortality and morbidity estimates.

\subsection{What Are the Ways to Do Randomization?}

\subsubsection{The Methods of Randomization in a Clinical Trial}

Blinding refers to keeping trial subjects, doctors, and trial-related persons or data collectors unaware of the allocated intervention to eliminate bias.

Various methods of randomization are used:

1. Simple randomization-Using techniques like a pack of cards, flipping of a coin (even - control, odd — treatment), or throwing dice (e.g., below and equal to 3control, over 3-treatment) can be used. 
2. Random allocation is done using random number tables.

3. Block randomization-This method is designed to randomize subjects into groups.

4. Stratification randomization-This is a two-stage procedure where the first randomization is done according to clinical features which may influence the outcome and in the second a particular treatment is given to that arm.

5. Minimization-The aim of minimization is to minimize the imbalance between the number of patients in each treatment over a number of factors.

\subsection{What Are Other Considerations Before Conditional Trial?}

\subsubsection{Ethical Considerations}

IRB approval must be discussed and the data collection protocol's adherence to the World Medical Association Declaration of Helsinki on Ethical Principles for Medical research involving Human Subjects should be discussed.

\subsubsection{Clinical Trial Registration}

Clinical trials are registered mainly to avoid publication bias and selective reporting. In addition, clinical trial registries serve to increase transparency and access to clinical trials for the public. There have been recently much efforts to increase standardization of registration of clinical trials with the WHO aim to 'achieving consensus on both the minimal and the optimal operating standards for trial registration'. The largest and most frequently used repository of trials is ClinicalTrials.gov, run by the United States National Library of Medicine (NLM). Others include Australian New Zealand Clinical Trials Registry (ANSCTR), the International Standard Randomised Controlled Trial Number in the UK, and the Clinical Trials Registry in India.

\subsubsection{Details of Primary Investigator, Co-Investigator, Internal and External Collaborators}

Rich and salubrious scholarship is obtained through active collaborations between multiple centres of research. Individual and institutional collaborations should be listed.

\subsubsection{Budget}

This is an estimation of the expenses which are likely to be incurred during the study period. It should include travel costs, costs of reagents, instrumentation, 
special software, and manpower. Each cost should be justified and if the research is expected to run for several years, the inflation cost should also be added.

\subsection{What Are the Various Extramural Source of Funding for Doctors for a Research Project?}

Usually, there are two mechanisms for grants, i.e., sole-source grants commissioned grants for pre-qualified organizations, and competitive grants. Sole source grants are non-competitive with contractual arrangements whereas competitive grants are managed through call for proposal where individuals or organizations are required to go through a competitive process. The various funding agencies are given below. Besides the government authorities, many speciality associations also offer funding for MD, DM projects. Many universities and colleges have travel grants for students who present papers in national or international conferences. The details and age limits and inclusion criteria need to be checked on their websites (Table 12.3).

Table 12.3 Various funding agencies in India and Pakistan

\begin{tabular}{|c|c|c|}
\hline Agency & Details & Website \\
\hline $\begin{array}{l}\text { Department of } \\
\text { Biotechnology } \\
\text { (DBT) }\end{array}$ & $\begin{array}{l}\text { The department is under the Ministry of } \\
\text { Science and Technology } \\
\text { It was established in } 1986 \text { gave motivation to } \\
\text { the development of the field of modern } \\
\text { biology and biotechnology in India } \\
\text { Covers funding for basic research and for } \\
\text { Vaccines, Diagnostics, new Drug } \\
\text { Development, Human Genetics and Genome } \\
\text { Analysis, Stem Cell Biotechnology }\end{array}$ & $\begin{array}{l}\text { www.dbtindia.gov.in, } \\
\text { www.btisnet.gov.in, www. } \\
\text { dbtindia.gov.in/ } \\
\text { organisation/nodal.htm }\end{array}$ \\
\hline $\begin{array}{l}\text { University } \\
\text { Grants } \\
\text { Commission } \\
\text { (UGC) }\end{array}$ & $\begin{array}{l}\text { Universities have been the centres of research } \\
\text { University and college teachers need to be } \\
\text { supported to meet this requirement } \\
\text { For medical major and minor projects }\end{array}$ & www.ugc.ac.in \\
\hline $\begin{array}{l}\text { Higher Education } \\
\text { Commission } \\
\text { (HEC) }\end{array}$ & $\begin{array}{l}\text { HEC offers numerous grants and challenges } \\
\text { to assist researchers financially }\end{array}$ & $\begin{array}{l}\text { https://www.hec.gov.pk/ } \\
\text { english/services/RnD/ } \\
\text { Pages/Research-Grants. } \\
\text { aspx }\end{array}$ \\
\hline $\begin{array}{l}\text { Pakistan Science } \\
\text { Foundation } \\
\text { (PSF) }\end{array}$ & $\begin{array}{l}\text { PSF offers grants to universities and other } \\
\text { R\&D organizations, both for projects on an } \\
\text { individual basis or to group of scientists }\end{array}$ & $\begin{array}{l}\text { http://www.psf.gov.pk/ } \\
\text { researchSupport.aspx }\end{array}$ \\
\hline $\begin{array}{l}\text { Pakistan Health } \\
\text { Research Council } \\
\text { (PHRC) }\end{array}$ & $\begin{array}{l}\text { Offers grants in health and disease reach to } \\
\text { guide policy decisions }\end{array}$ & $\begin{array}{l}\text { https://phrc.org.pk/ } \\
\text { research-grant.html }\end{array}$ \\
\hline $\begin{array}{l}\text { Indian Council of } \\
\text { Medical } \\
\text { Research } \\
\text { (ICMR) }\end{array}$ & $\begin{array}{l}\text { Have various schemes like Ad-hoc Research } \\
\text { Schemes, Senior / Junior Fellowships, or } \\
\text { Emeritus Medical Scientist Scheme } \\
\text { Financial assistance to MD/MS/DM/MCH } \\
\text { thesis programme } \\
\text { Grant-in-aid for organizing Seminars / } \\
\text { Symposia /Work shops }\end{array}$ & www.icmr.nic.in \\
\hline
\end{tabular}




\subsection{Conclusions}

- The application for study proposal should be well-structured and free from any grammatical and scientific errors.

- Not all research projects receive funding.

- For protocol and research grants, the methodology should be written in the future tense.

- Use references in this section for the definition of various terms related to your study.

- Write comprehensively describing minute details of the experiment.

\section{References}

1. Al-Riyami A. How to prepare a Research Proposal. Oman Med J. 2008;23(2):66-9.

2. Horiuchi S, Rattana S, Saysanasongkham B, Kounnavongsa O, Kubota S, Cayrol J, et al. Study protocol of a cluster randomized controlled trial to evaluate effectiveness of a system for maintaining high-quality early essential newborn care in Lao PDR. BMC Health Serv Res. 2018;18(1):489.

3. Erdemir F. How to write a materials and methods section of a scientific article? Turk J Urol. 2013;39(Suppl 1):10-5.

4. Akrani G. Difference between primary and secondary data in 16 points; 2014. https://kalyancity.blogspot.com/2014/12/difference-between-primary-and_1.html. Accessed 1-11-2020.

5. Bhutta ZA, Soofi S, Cousens S, Mohammad S, Memon ZA, Ali I, et al. Improvement of perinatal and newborn care in rural Pakistan through community-based strategies: a clusterrandomised effectiveness trial. Lancet. 2011;377(9763):403-12.

Open Access This chapter is licensed under the terms of the Creative Commons Attribution 4.0 International License (http://creativecommons.org/licenses/by/4.0/), which permits use, sharing, adaptation, distribution and reproduction in any medium or format, as long as you give appropriate credit to the original author(s) and the source, provide a link to the Creative Commons license and indicate if changes were made.

The images or other third party material in this chapter are included in the chapter's Creative Commons license, unless indicated otherwise in a credit line to the material. If material is not included in the chapter's Creative Commons license and your intended use is not permitted by statutory regulation or exceeds the permitted use, you will need to obtain permission directly from the copyright holder. 